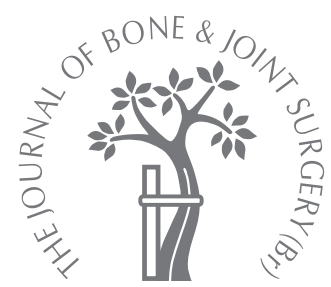

\title{
Ossicles associated with chronic pain around the malleoli of the ankle
}

S. H. Han, W. J. Choi, S. Kim, S.-J. Kim, J. W. Lee

From Yonsei University College of Medicine, Seoul, South Korea

In. H. Han, MD, PhD, Assistant Professor, Orthopaedic Surgeon

Department of Orthopaedic Surgery

Ajou University School of Medicine, Wonchon-Dong, Yeongtong-Gu, Suwon 443721, South Korea.

W. J. Choi, MD, Fellow, Orthopaedic Surgeon S.-J. Kim, MD, PhD Professor of Orthopaedic Surgery

J.W. Lee, $\mathrm{MD}, \mathrm{PhD}$ Associate Professor, Orthopaedic Surgeon Department of Orthopaedic Surgery

Yonsei University College of Medicine, 134 Shinchon-Dong, Seodaemun-gu, Seoul 120-752, South Korea.

S. Kim, MD, PhD, Assistant Professor, Radiologist Department of Radiology Yongdong Severance Hospital, 612 Eonjuro, Gangnam-gu, Seoul, South Korea.

Correspondence should be sent to Professor J. W. Lee; e-mail: ljwos@yuhs.ac

(C) 2008 British Editorial Society of Bone and Joint Surgery doi:10.1302/0301-620X.90B8. $20331 \$ 2.00$

$J$ Bone Joint Surg [Br] 2008;90-B:1049-54. Received 11 October 2007; Accepted after revision 2 April 2008

We undertook a retrospective review of 24 arthroscopic procedures in patients with symptomatic ossicles around the malleoli of the ankle. Most of the patients had a history of injury and localised tenderness in the area coinciding with the radiological findings. Contrast-enhanced three-dimensional fast-spoiled gradient-echo MRI was performed and the results compared with the arthroscopic findings. An enhanced signal surrounding soft tissue corresponding to synovial inflammation and impingement was found in 20 patients (83\%). The arthroscopic findings correlated well with those of our MRI technique and the sensitivity was estimated to be $91 \%$. At a mean follow-up of 30.5 months (20 to 86 ) the mean American Orthopaedic Foot and Ankle Society score improved from $\mathbf{7 4 . 5}$ to 93 points ( $p<0.001$ ). Overall, the rate of patient satisfaction was $88 \%$.

Our results indicate that symptomatic ossicles of the malleoli respond well to arthroscopic treatment.

Ossicles adjacent to the malleoli of the ankle may cause chronic pain. Various hypotheses have been proposed to explain their presence. It has been suggested that those found adjacent to the tip of the medial and lateral malleoli are abnormal accessory bones. Those appearing after epiphyseal closure and showing characteristics of fracture fragments possibly result from avulsion fractures. ${ }^{1-10}$ Opinions differ as to why intra-articular ossicles cause pain. Those in the knee or elbow do so by rubbing or irritating the subchondral bone. However, those around the ankle are within or attached to ligaments or soft tissues and have relatively reduced intra-articular mobility. Pain induced by these ossicles may be caused by some other mechanism.

Hasegawa et $\mathrm{al}^{6}$ and Bonnin and Bouysset ${ }^{11}$ found that removing intra-articular ossicles in the ankle arthroscopically gave good results. However, information on the diagnosis, radiological characteristics and management of pain related to ossicles around the ankle is still limited.

We observed enhancement of the signal in ossicles around the malleolus by applying three-dimensional (3-D) contrast-enhanced, fat-suppressed, fast-gradient-recalled acquisition in the steady state with radio-frequencyspoiling MRI which had been previously introduced for the diagnosis of intra-articular synovitis or soft-tissue impingement. ${ }^{12,13}$ After arthroscopic examination and treatment, we analysed the diagnostic usefulness of this technique. In addition, the therapeutic efficiency of arthroscopic treatment and its relationship to other clinical factors was evaluated.

\section{Patients and Methods}

Between March 2000 and December 2004, we studied 24 patients who had been diagnosed with ossicles which might have been due to avulsion fractures of a malleolus. The diagnosis was based on a history of trauma to the ankle, symptoms appearing after epiphyseal closure, a congruent shape of the ossicles with the relevant malleolus on radiological examination and cowas based on a history of trauma to the ankle, symptoms appearing after epiphyseal closure, a congruent shape of the ossicles with the relevant malleolus on radiological examination and continuity with the adjacent anterior talofibular, calcaneofibular or deep deltoid ligaments. ${ }^{5,8-10}$ The history of the injury, the frequency of sprains, the presence or absence of local tenderness and its location, and evidence of instability were evaluated. Trauma was categorised as an inversion type, an eversion type or other. The location of local tenderness was graded as anterior, anterolateral, inferolateral, posterolateral, posterior, anteromedial, medio-inferior or posteromedial. Local tenderness was determined by digital examination with the ankle in the neutral position. Patients who expe- 
Table I. Clinical details and results in the 24 patients

\begin{tabular}{|c|c|c|c|c|c|c|c|c|c|c|c|}
\hline \multirow[b]{2}{*}{ Case } & \multirow[b]{2}{*}{ Location } & \multirow[b]{2}{*}{ Gender } & \multirow{2}{*}{$\begin{array}{l}\text { Age } \\
\text { (yrs) }\end{array}$} & \multirow[b]{2}{*}{ Side } & \multirow{2}{*}{$\begin{array}{l}\text { Mean duration of } \\
\text { symptoms (mths) }\end{array}$} & \multirow{2}{*}{$\begin{array}{l}\text { MRI } \\
\text { grade }\end{array}$} & \multirow{2}{*}{$\begin{array}{l}\text { Combined } \\
\text { lesion* }\end{array}$} & \multirow{2}{*}{$\begin{array}{l}\text { Follow-up } \\
\text { (mths) }\end{array}$} & \multicolumn{2}{|l|}{ AOFAS $^{\dagger}$ score } & \multirow[b]{2}{*}{ Clinical results } \\
\hline & & & & & & & & & Pre-operative & Post-operative & \\
\hline 1 & Lateral & $\mathrm{M}$ & 28 & $\mathrm{R}$ & 6 & IV & - & 40 & 72 & 94 & Good \\
\hline 2 & Lateral & $\mathrm{M}$ & 21 & $\mathrm{R}$ & 6 & III & - & 39 & 74 & 100 & Excellent \\
\hline 3 & Lateral & $\mathrm{M}$ & 19 & $\mathrm{~L}$ & 20 & IV & $\begin{array}{l}\text { Syndesmosis } \\
\text { injury }\end{array}$ & 86 & 78 & 100 & Excellent \\
\hline 4 & Lateral & $\mathrm{M}$ & 14 & $\mathrm{R}$ & Unknown & III & OCL medial & 42 & 80 & 94 & Good \\
\hline 5 & Medial & $\mathrm{M}$ & 34 & $\mathrm{R}$ & 70 & IV & - & 30 & 78 & 97 & Excellent \\
\hline 6 & Bimalleoli & $\mathrm{M}$ & 27 & $\mathrm{~L}$ & 96 & IV & - & 30 & 74 & 90 & Good \\
\hline 7 & Lateral & $\mathrm{M}$ & 21 & $\mathrm{R}$ & 30 & III & OCL medial & 32 & 80 & 95 & Excellent \\
\hline 8 & Lateral & $\mathrm{M}$ & 18 & $\mathrm{R}$ & 27 & IV & - & 27 & 74 & 88 & Good \\
\hline 9 & Lateral & $\mathrm{M}$ & 34 & $\mathrm{R}$ & 40 & II & OCL lateral & 26 & 72 & 88 & Fair \\
\hline 10 & Lateral & $\mathrm{M}$ & 21 & $\mathrm{~L}$ & 6 & III & $\begin{array}{l}\text { Syndesmosis } \\
\text { injury }\end{array}$ & 30 & 70 & 90 & Good \\
\hline 11 & Lateral & $\mathrm{F}$ & 29 & $\mathrm{~L}$ & 16 & I & - & 26 & 70 & 78 & Poor \\
\hline 13 & Medial & $\mathrm{M}$ & 26 & $\mathrm{R}$ & 80 & III & - & 30 & 78 & 90 & Good \\
\hline 14 & Lateral & $\mathrm{F}$ & 15 & $\mathrm{~L}$ & 30 & IV & - & 28 & 80 & 100 & Excellent \\
\hline 15 & Lateral & $\mathrm{M}$ & 22 & $\mathrm{R}$ & 26 & I & - & 26 & 78 & 97 & Good \\
\hline 16 & Medial & $\mathrm{M}$ & 48 & $\mathrm{~L}$ & 26 & III & - & 26 & 68 & 94 & Excellent \\
\hline 17 & Lateral & $\mathrm{F}$ & 31 & $\mathrm{R}$ & 24 & 1 & - & 24 & 70 & 90 & Good \\
\hline 18 & Lateral & $\mathrm{F}$ & 15 & $\mathrm{R}$ & 22 & IV & - & 22 & 78 & 100 & Excellent \\
\hline 19 & Lateral & $\mathrm{F}$ & 17 & $\mathrm{~L}$ & 20 & III & - & 20 & 70 & 100 & Excellent \\
\hline 20 & Lateral & $\mathrm{M}$ & 23 & $\mathrm{~L}$ & 24 & IV & OCL lateral & 24 & 74 & 100 & Excellent \\
\hline 21 & Lateral & $\mathrm{M}$ & 23 & $\mathrm{R}$ & 24 & IV & OCL medial & 24 & 80 & 100 & Excellent \\
\hline 22 & Lateral & $\mathrm{F}$ & 28 & $\mathrm{R}$ & 24 & IV & - & 24 & 75 & 98 & Excellent \\
\hline 23 & Lateral & $\mathrm{F}$ & 50 & $\mathrm{~L}$ & 24 & IV & - & 20 & 72 & 88 & Good \\
\hline 24 & Lateral & $\mathrm{F}$ & 56 & $\mathrm{~L}$ & 20 & III & - & 28 & 78 & 90 & Good \\
\hline
\end{tabular}

* OCL, osteochondral lesion; TCC, talocalcaneal coalition

† AOFAS, American Orthopaedic Foot and Ankle Society

rienced sudden pain in the ankle due to an injury which occurred within six months or who had chronic instability of the ankle were excluded. All the patients received conservative treatment for more than three months. If the pain persisted, arthroscopic surgery was performed.

There were 16 males and eight females, with a mean age of 26.4 years (14 to 56). The right ankle was affected in 14 patients and the left in ten. The mean duration of symptoms before surgery was 29.7 months (6 to 96) (Table I). The patients were followed up for a mean of 30.5 months (20 to 86).

Radiological examination. Conventional radiographs and MR scans were taken for all patients. The location of the ossicles in the anteroposterior radiograph was categorised as level A for those below the tip of the malleolus and level B when on the articular side. ${ }^{6}$ The longest fragments as seen on the anteroposterior radiographs were measured and described as small for those $<5 \mathrm{~mm}$, medium for those between $5 \mathrm{~mm}$ and $10 \mathrm{~mm}$ and large for those $\geq 10 \mathrm{~mm}$. The form of the ossicles was classified as either angular or roundoval when in contact with the malleolus. The angular form was further divided into sharp and blunt depending on the surface contacting the malleolus. The presence or absence of an osteosclerotic rim on the surface in contact with the malleolus was also determined. The mean values for radio- logical assessment were evaluated by three examiners $(\mathrm{SHH}$, WJC, SK).

MR scans were obtained using a $1.5 \mathrm{~T}$ superconducting MR scanner (Sigma; GE Medical Systems, Milwaukee, Wisconsin) at $3 \mathrm{~mm}$ intervals using a $20 \mathrm{~cm}$ short coil with the foot in the neutral position. Spin-echo was used for $\mathrm{T}_{1}$-enhanced imaging (TR/TE, 517/9; matrix, $256 \times$ 192 , two signals acquired) and $\mathrm{T}_{2}$-enhanced imaging (TR/ TE, 2000/70; matrix $256 \times 192$, two signals acquired) to obtain sagittal, coronal and axial images (Fig. 1). In order to observe the level of inflammation and thickening of the joint capsule in the vicinity of the ossicles, additional coronal imaging was performed using a 3-D CE fat-suppressed fast-gradient-recalled MR technique. ${ }^{12,13}$ The enhancement on MRI was categorised as follows: grade I, none; grade II, linear; grade III, focal nodular; and grade IV, irregular nodular. Grade III or grade IV indicated synovitis or soft-tissue impingement. The MR scan readings were analysed by two radiologists (including SK).

Arthroscopic surgery. The arthroscopic procedures were undertaken by one surgeon (JWL). The knee was flexed over the end of the operating table and the ankle suspended. Traction with a load of $6 \mathrm{~kg}$ to $8 \mathrm{~kg}$ was applied through an ankle harness to expand the joint space. Standard anteromedial and anterolateral portals were used with 


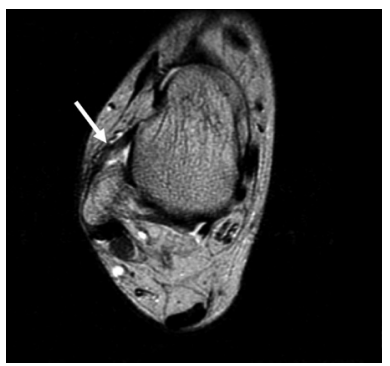

Fig. 1a

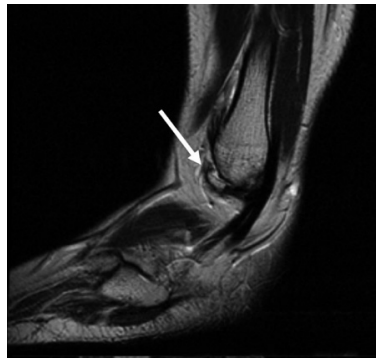

Fig. 1b

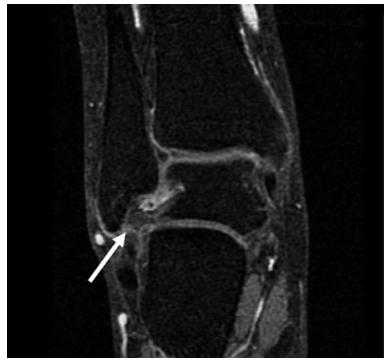

Fig. 1c

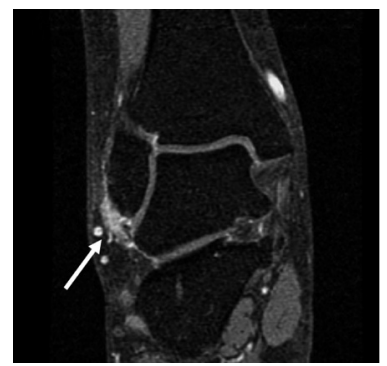

Fig. 1d

Case 21. MR scans of the lateral malleolus of a 23-year-old man, a) the $T_{1}$-weighted axial scan showing an ossicle in the thickened anterior talofibilar ligament, suggestive of an avulsion fracture (arrow), b) a sagittal $T_{2}$-weighted (TR/TE, 2000/70) scan showing a small bone fragment anterior to the lateral malleolus (arrow), c) and d) coronal contrast-enhanced frequency-selective 3-D fat-suppressed, fast-gradient-recalled scans $\left(20.9 / 2.2\right.$; flip angle, $\left.15^{\circ}\right)$ showing a small bone fragment inferior to the tip of the lateral malleolus with enhancement. Enhancing tissue is seen lateral to the bone fragment (arrow).

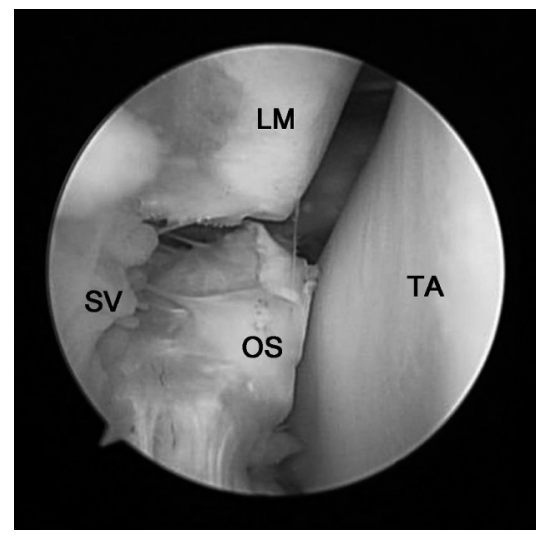

Fig. 2a

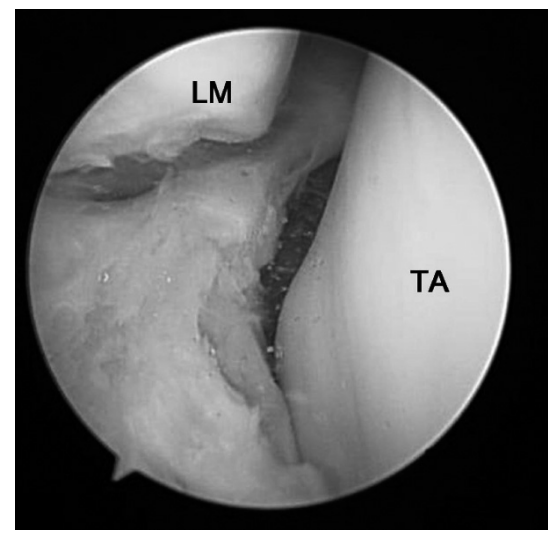

Fig. $2 b$

Case 21. Arthroscopy showing a) the presence of an ossicle and soft tissue in the lateral gutter area of the ankle before removal and debridement and $b$ ) the lateral gutter area after removal and debridement of the ossicle and soft tissue (LM, lateral malleolus; OS, ossicle; SV, synovitis; TA, talus).

Table II. Grade of contrast-enhancement of 3-D contrast-enhanced fatsuppressed, fast-gradient-recalled MRI in the 24 patients

\begin{tabular}{llc}
\hline Grade & Description & Number of patients (\%) \\
\hline I & No enhancement & $3(13)$ \\
II & Linear enhancement & $1(4)$ \\
III & Focal nodular enhancement & $9(37)$ \\
IV & Irregular nodular enhancement & $11(46)$ \\
\hline
\end{tabular}

additional inferior (anterolateral or anteromedial) portals $1.5 \mathrm{~cm}$ below the standard sites as needed. ${ }^{7}$ After inserting the arthroscope, the lesions in the joint, synovitis, softtissue impingement, osteochondral lesions of the talus and injury to the syndesmosis were examined. ${ }^{14,15}$ The relationship of the ossicles, the malleolus, the surrounding soft tissue and the ligaments were examined using a probe. Ossicles were removed using pituitary forceps and a motorised shaver to reduce damage to the ligaments when separating the fragments from soft tissue (Fig. 2).

After operation the patients were allowed to bear weight as tolerated, and muscle stimulating and strengthening exercises were encouraged for three weeks to achieve a normal range of movement. High impact sports were allowed 12 weeks after surgery.

The American Orthopaedic Foot and Ankle Society (AOFAS) ankle-hindfoot scale ${ }^{16}$ (pain, 40 points; function, 50 points; alignment 10 points) was used to evaluate the clinical outcomes and the criteria of Meislin et $\mathrm{al},{ }^{17}$ to assess patient satisfaction. 


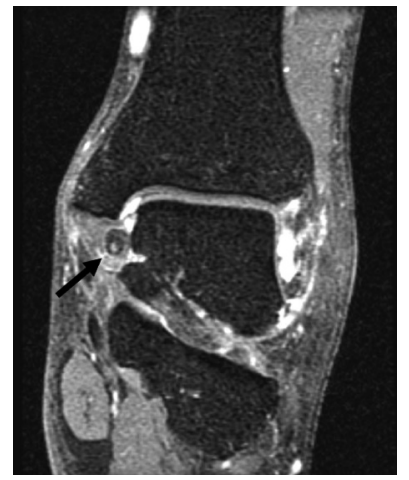

Fig. 3a

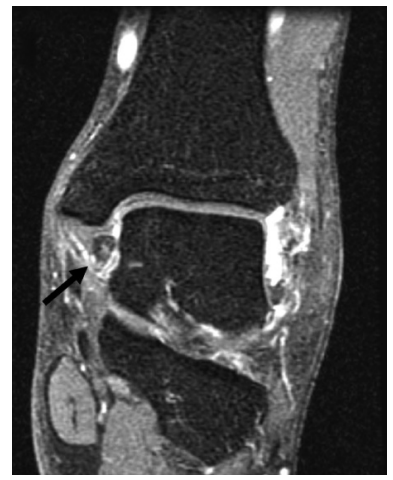

Fig. $3 b$

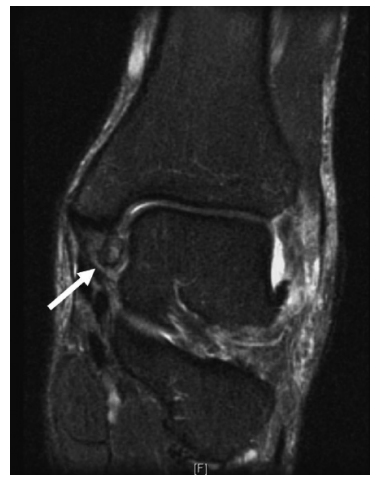

Fig. 3c

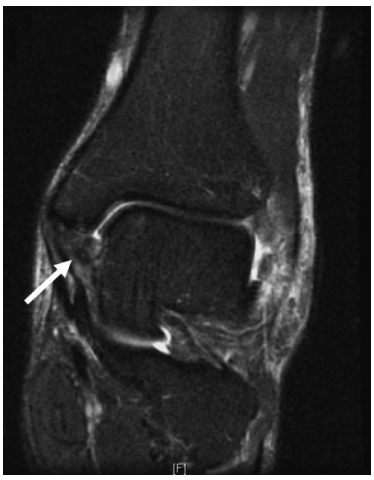

Fig. 3d

Case 13. MR scans of an ossicle around the tip of the medial malleolus of a 26-year-old man, a) and b) coronal contrast-enhanced frequencyselective 3-D fat-suppressed, fast-gradient-recalled scans $\left(20.9 / 2.2\right.$; flip angle, $\left.15^{\circ}\right)$ showing a small bone fragment medial to the medial talar wall attached to the deep deltoid ligament. There is enhancement of the bone fragment and the tissue medial to this fragment (black arrows), c) and d) coronal frequency-selective fat-suppressed fast spin-echo $T_{2}$-weighted images (TR/TE, 3000/75) showing a small bone fragment medial to the medial talar wall attached to the deep deltoid ligament. The bone fragment shows slight oedema, but surrounding enhancing tissue is not well depicted by the fat-suppressed fast-gradient-recalled MR sequence (white arrows).

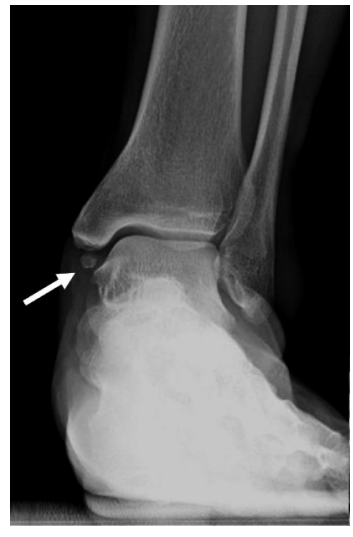

Fig. $4 \mathrm{a}$

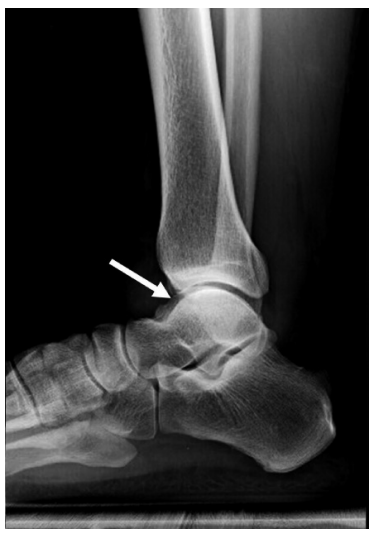

Fig. $4 b$

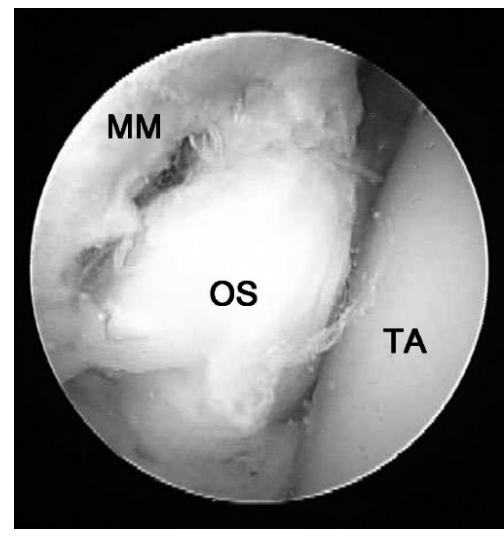

Fig. 4c

Case 13. a) and b) plain radiographs and c) arthroscopic appearance of an ossicle (white arrow) around the tip of the medial malleolus (MM, medial malleolus; OS, ossicle; TA, talus).

Statistical analysis. The Mann-Whitney U test was used for statistical analysis and the results were considered to be statistically significant if the p-value was $\leq 0.05$.

\section{Results}

Clinical evaluation. At presentation 22 of the 24 patients had pain after lengthy exercise. One patient could not recall a history of trauma, but the others had experienced an inversion injury. Local tenderness was observed in all cases, most commonly at the anterolateral joint area in 18 patients $(75 \%)$. Tenderness was found at the anteromedial joint line in eight patients and at the inferolateral joint line in two. Pain and tenderness were present on both the lateral and medial sides in five patients. The tender points corresponded to the location of ossicles and concomitant conditions such as an osteochondral lesion of the talus and talocalcaneal coalition.

Radiological evaluation. Seven patients (29\%) had ossicles at level $\mathrm{A}$ and $17(71 \%)$ at level $\mathrm{B}$. The size of the ossicles was $<5 \mathrm{~mm}$ in 11 patients $(46 \%)$, between $5 \mathrm{~mm}$ and $10 \mathrm{~mm}$ in $11(46 \%)$, and $>10 \mathrm{~mm}$ in two $(8 \%)$. They were sharply angular without an osteosclerotic rim in 12 patients $(50 \%)$, bluntly angular without an osteosclerotic rim in seven $(29 \%)$, round-oval without an osteosclerotic rim in four $(17 \%)$ and round-oval with an osteosclerotic rim in one $(4 \%)$. There were unilateral lesions at the lateral malleolus in 20 patients $(83 \%)$, a single lesion at the medial malleolus in three $(13 \%)$ and a bimalleolar lesion in one $(4 \%)$. Two patients had two ossicles at the tip of the lateral malleolus. 
MRI showed thickening of the anterior talofibular ligament in 14 patients $(58 \%)$ and a ruptured anterior talofibular ligament in three $(13 \%)$. Enhanced signs around the ossicles in 3-D contrast-enhanced fat-suppressed, fastgradient-recalled MR scans were grade I in three patients $(13 \%)$, grade II in one $(4 \%)$, grade III in nine $(37 \%)$ and grade IV in 11 (46\%) (Table II). Positive enhancement of the signal was present in 20 patients, reflecting synovitis and hypertrophic soft-tissue impingement around the ossicles. Arthroscopic findings and associated lesions. There were 15 patients $(63 \%)$ with spaces between the malleolus and the fragments seen on arthroscopic examination. A further nine $(37 \%)$ had a space between the malleolus and the fibrous tissue with bone fragments fixed within the thickened fibrous tissues or ligaments. There were 22 patients $(92 \%)$ with synovitis and hypertrophic soft-tissue impingement around the ossicles. These appearances correlated well with the MR scans with a sensitivity of $91 \%$, since 20 of the 22 cases had been correctly diagnosed by 3-D contrast-enhanced fat-suppressed, fast-gradient-recalled MRI (Figs 3 and 4). Osteochondral lesions of the talus were present in five patients, in three on the medial and in two on the lateral side. Two patients showed injuries to the distal tibiofibular syndesmosis and two had anterior bony spurs.

The mean ankle-hindfoot AOFAS score increased from 74.5 points (66 to 80 ) pre-operatively to 93 points ( 78 to $100)$ after operation $(\mathrm{p}<0.05)$. The degree of patient satisfaction was excellent in 11, good in ten, fair in two and poor in one. The latter three patients had a concomitant lesion of talocalcaneal coalition or no signal enhancement of the soft tissue around the ossicles on MRI.

There were no major or minor complications such as superficial skin infections or nerve injuries.

\section{Discussion}

The diagnosis and treatment of the chronic ankle pain associated with ossicles have not yet been established. The development of ossicles has been attributed either to an abnormal centre of ossification or to an avulsion injury. ${ }^{1-10}$ A secondary centre for ossification for the medial and lateral malleolus has been described in $20 \%$ and $1 \%$, respectively, of children aged between six and 12 years. ${ }^{18}$ This secondary centre fuses by the age of 14 years. Ossicles found after this age have been described as avulsion fragments associated with trauma and recurrent injury to the ankle. In addition, Leimbach ${ }^{19}$ suggested that a history of ankle trauma was an important factor in the differential diagnosis of a secondary ossification centre and an avulsion fracture. In our study, all the patients with chronic ankle pain related to trauma were over 14 years of age. Radiographs showed that most of the bony fragments were irregularly shaped and compatible with the inferior border of the malleolus. MRI demonstrated that many ossicles were attached to surrounding ligaments. We considered that the ossicles in our patients were remnants of avulsion fractures. Most patients had a history of an inversion injury and their symptoms settled after arthroscopically-assisted removal of the ossicles. All of our patients complained of local tenderness near the site of the ossicle on arthroscopic or radiological examination.

Some studies have described an ossicle at the lateral malleolus which was associated with recurrent instability of the ankle and recommended that its removal should be combined with reconstruction of the ligament. ${ }^{5,20}$ In our patients, no direct relationship between instability of the ankle and the presence of ossicles was established. There is a possibility that instability may arise after excessive debridement of the ligaments, but none was observed in our patients. Debridement was carried out with great care in order to minimise damage to the ligaments.

There are several reports that describe the major characteristics of avulsion lesions. ${ }^{4,6,9}$ These include irregularity of the surface in contact with the malleolus as seen on radiographs, ${ }^{6,9}$ the location of the fragment, ${ }^{4,9}$ a sharp angular shape ${ }^{6}$ and conformity with the fracture surface of the malleolus. ${ }^{4,9}$ Hasegawa et $\mathrm{al}^{6}$ demonstrated a relationship between avulsion of the calcaneofibular and anterior talofibular ligaments radiologically in four level A (29\%) and ten level B patients $(71 \%)$. In our study most were sharply angular fragments without an osteosclerotic rim similar to those described by Hasegawa et al. ${ }^{6}$ Bone scans or arthrograms have been recommended as additional tests, ${ }^{6,9}$ but the 3-D contrast-enhanced fat-suppressed, fastgradient-recalled MR technique showed a high efficiency in evaluating ossicles caused by avulsion fractures with accompanying chronic pain in the ankle. The pain appeared to be derived from the recurrent irritation of ossicles on the surrounding soft tissue which induced synovitis and hypertrophic soft-tissue impingement. The removal of these pathological tissues with the ossicles gave a satisfactory outcome. Other studies ${ }^{3,11}$ have had similar results.

No benefits in any form have been received or will be received from a commercial party related directly or indirectly to the subject of this article.

\section{References}

1. Berg EE. The symptomatic os subfibulare: avulsion fracture of the fibula associated with recurrent instability of the ankle. J Bone Joint Surg [Am] 1991;73-A:1251-4.

2. Bröstrom L. Sprained ankles v. treatment and prognosis in recent ligament ruptures. Acta Chir Scand 1996;132:537-50.

3. Busconi BD, Pappas AM. Chronic, painful ankle instability in skeletal immature athletes: ununited osteochondral fractures of the distal fibula. Am J Sports Med 1996;24:647-51.

4. Coral A. Os subtibiale mistaken for a recent fracture. Br Med J 1986;292:1571-2.

5. Griffiths JD, Menelaus MB. Symptomatic ossicles of the lateral malleolus in children. J Bone Joint Surg [Br] 1987;69-B:317-19.

6. Hasegawa A, Kimura M, Tomizawa S, Shirakura K. Separated ossicles of the lateral malleolus. Clin Orthop 1996;330:157-65.

7. Kono T, Ochi M, Takao M, et al. Symptomatic os subfibulare caused by accessory ossification: a case report. Clin Orthop 2002;399:197-200.

8. Love SM, Ganey T, Ogden JA. Postnatal epiphyseal development: the distal tibia and fibula. J Pediatr Orthop 1990;10:298-305.

9. Ogden JA, Lee J. Accessory ossification patterns and injuries of the malleoli. J Pediatr Orthop 1990;10:306-16.

10. Paterson FW, Benjamin A. Instability of the ankle due to a separate centre of ossification in the lateral malleolus. Injury 1984;15:330-3.

11. Bonnin M, Bouysset M. Arthroscopy of the ankle: analysis of results and indications on a series of 75 cases. Foot Ankle Int 1999;20:744-51. 
12. Huh YM, Suh JS, Song HT. Synovitis and soft tissue impingement of the ankle: assessment with enhanced three-dimensional FSPGR MR imaging. J Magn Reson Imaging 2004;19:108-16.

13. Lee JW, Suh JS, Huh YM, Moon ES, Kim SJ. Soft tissue impingement syndrome of the ankle: diagnostic efficacy of MRI and clinical results after arthroscopic treatment. Foot Ankle Int 2004;25:896-902.

14. Han SH, Lee JW, Kim S, Suh JS, Choi YR. Chronic tibiofibular syndesmosis injury: the diagnostic efficiency of magnetic resonance imaging and comparative analysis of operative treatment. Foot Ankle Int 2007;28:336-42.

15. Ogilvie-Harris DJ, Reed SC. Disruption of the ankle syndesmosis: diagnosis and treatment by arthroscopic surgery. Arthroscopy 1994;10:561-8.
16. Kitaoka HB, Alexander IJ, Adelaar RS, et al. Clinical rating systems for the anklehindfoot, midfoot, hallux, and lesser toes. Foot Ankle Int 1994;15:349-53.

17. Meislin RJ, Rose DJ, Parisien JS, Springer S. Arthroscopic treatment of synovial impingement of the ankle. Am J Sports Med 1993;21:186-9.

18. Powell HDW. Extra centre of ossification for the medial malleolus in children: incidence and significance. J Bone Joint Surg [Br] 1961;43-B:107-13.

19. Leimbach G. Beiträge zur Kenntnis der inkonstanten Skeletelmente des Tarsus: (Akzessorische Fusswurzelkaochen): (Untersuchunger an 500 Köntgenbildern der Chir Universitätsklinik zu Jena). Arch Orthop Trauma Surg 1937;38:431-48.

20. DiGiovanni BF, Fraga CJ, Cohen BE, Shereff MJ. Associated injuries found in chronic lateral ankle instability. Foot Ankle Int 2000;21:809-15. 